Article

\title{
The Impact of Early Basal Leaf Removal at Different Sides of the Canopy on Aglianico Grape Quality
}

\author{
Luigi Tarricone $^{1, *} \mathbb{D}$, Michele Faccia ${ }^{2} \mathbb{D}$, Gianvito Masi ${ }^{1}$ and Giuseppe Gambacorta ${ }^{2}$ \\ 1 CREA, Council for Agricultural Research and Economics, Research Center for Viticulture and Enology, \\ via Casamassima 148, 70010 Bari, Italy; gianvito.masi@crea.gov.it \\ 2 Department of Soil, Plant and Food Science (DISSPA), University of Bari Aldo Moro, via Amendola 165/A, \\ 70126 Bari, Italy; michele.faccia@uniba.it (M.F.); giuseppe.gambacorta@uniba.it (G.G.) \\ * Correspondence: luigi.tarricone@crea.gov.it
}

Received: 23 October 2020; Accepted: 11 December 2020; Published: 14 December 2020

\begin{abstract}
It is known that early removal of basal leaves improves the exposure of cluster to direct sunlight and UV radiation, which positively influence the phenolic compounds and anthocyanin concentration of berries. This study was carried out to evaluate the effect of leaf removal applied before flowering to the basal zone of the canopy at different sides (fruit-zone north canopy side, south canopy side and north-south canopy side, respectively) of Aglianico vines trained to vertical shoot position system and row oriented to east-west (EW). The study was conducted in the controlled and guaranteed designation of origin (CGDO) Castel del Monte area (Apulia region, Italy). The treatment did not affect yield per vine, and nor sugar, $\mathrm{pH}$, and total acidity of grapes. When it was applied to the basal south canopy side, the concentration of proanthocyanidins and total polyphenols of grapes increased, as well as antioxidant activity. In particular, anthocyanins content, determined by HPLC, increased by $20 \%$ with respect to control when treatment was applied to south and north-south canopy sides. Interaction between season period and treatment was found for all anthocyanins except for petunidin-3-coumaroyl-glucoside. Basal leaf removal applied to the north canopy side caused an increase in malvidin-3-O-glucoside content in grapes in 2016 and 2018, but not in 2017. Our results indicate that basal leaf removal (six basal leaves removed from the base of the shoots) before flowering (BBCH 57) can be used as an effective strategy to improve grape total polyphenols, anthocyanins concentration and antioxidant activity in vineyards cultivated under warm climate conditions. The treatment could represent a sustainable alternative to manual cluster thinning since it does not reduce yield per vine and can be performed mechanically.
\end{abstract}

Keywords: leaf removal; row orientation; grape yield; berry composition; polyphenols; antioxidant activity; anthocyanin profile

\section{Introduction}

The colour of grape berry skin is highly influenced by the canopy microclimate in terms of air temperature, sunlight exposure and air circulation. It was demonstrated that low light conditions inhibit berry colour development, while temperatures above $35^{\circ} \mathrm{C}$ compromise the accumulation of anthocyanins on the skin [1,2]. Nowadays, global warming is the main driver of the changes in the geographical distribution of viticulture in the world. Climate change is exerting strong effects on grapevine phenological phases, especially on grape ripening dynamics and the connected berry composition and the wine style. The increased frequency of summer days with air temperature exceeding $35^{\circ} \mathrm{C}$, a critical threshold for vine physiology, negatively impacts on the grapevine water status and normal ripening. Additionally, it might cause a reduction in titratable acidity, anthocyanin content and aromatic compounds in berries, with negative consequences on the freshness and aromatic 
complexity of wine. In addition to this, dry air exacerbates leaves and berries sunburn phenomena [3,4]. According to the most optimistic scenario of climate change, the temperatures should rise between $0.3^{\circ} \mathrm{C}$ and $1.7^{\circ} \mathrm{C}$ by the end of this century, whereas the pessimistic scenario predicts a maximum increase of $4.8^{\circ} \mathrm{C}$ [5]. It is known that air temperature affects gene expression of grapevines and enzymatic activity of primary and secondary metabolisms that determine grape ripening and berry chemical composition [6]. All agronomic practices that influence the canopy microclimate and the grape yield to leaf area ratio may influence the berry primary and secondary metabolites [7-10]. A research study on the Montepulciano variety demonstrated that shoot thinning carried out each year at the end of May and the beginning of June improved the berry chemical composition and reduced canopy density but had a negative effect on the yield per vine. When the treatment was combined with pre flowering leaf removal and cluster thinning, total soluble solids, anthocyanin concentration and phenolic substances increased at harvest [11]. In Bobal and Tempranillo varieties, late leaf removal before veràison (all the mature apical leaves of the main shoots and lateral shoots starting from the second node above the bunches were manually removed) reduced yield per vine, total soluble solids, accumulation of anthocyanins and wine colour [12]. Bubola et al. [13] found that both manual and mechanical leaf defoliation applied at the pea-size stage on Istrian Malvasia vines increased berry sugar content and decreased titratable acidity in grape juice. Improving the exposure of clusters to direct sunlight favoured malic acid decomposition and increased the must sugar/acid ratio. Leaf removal applied at the pea-size stage from the $50 \mathrm{~cm}$ basal zone of the shoot to the node above the apical cluster reduced soluble solids and sugar content per berry and decreased titratable acidity as a consequence of the faster rate of malic acid metabolism. Furthermore, the vine pruning weight decreased by topping and leaf defoliation, probably because of decreased carbohydrate availability from the leaves. Both topping and leaf removal caused a reduction in whole-grapevine photosynthesis immediately after the treatment, and leaf removal had a negative effect on vine growth [14]. Leaf removal applied to pea-size berries on Negroamaro vines enhanced grape ripeness and, consequently, increased the flavour of wine [15]. A study on Merlot vines demonstrated that leaf removal before flowering had no effects on tannin and anthocyanin concentrations in grapes but reduced the concentration of 3-isobutyl-2-methoxypyrazine in berries and wine. Other results related to pre-bloom leaf removal were the reduction in cluster compactness, weight and yield, lower incidence of Botrytis bunch rot and an improvement in wine colour intensity. The same results were obtained applying leaf removal after flowering but without a decrease in yield [16].

Basal defoliation, defined as the practice of leaf removal in the cluster zone, is one of the most common canopy practices applied to modify fruit-zone microclimates, and the impact of the timing and intensity of this practice differs across varieties and climate. Basal leaf removal was effective to reduce foliage cover (dense canopy), enhancing cluster light exposure and canopy porosity, and controlling the incidence of bunch root disease [17,18]. Canopy management (shoot trimming, cluster thinning and leaf removal) causes changes in fruit-zone microclimates and exerts an effect on grape and wine quality in relation to the primary and secondary metabolites' composition. Additionally, sunlight-exposed clusters by leaf removal are generally characterized by higher soluble solids, anthocyanins, flavonols and lower malic acid and titratable acidity compared with the control vines [19,20]. Basal defoliation is widely used in cool climate viticulture, which is characterized by low solar heat accumulation and high air humidity and rainfall [21]. The timing and intensity of basal leaf removal has an important effect on berry composition: leaf removal applied at veràison (late defoliation) increases the incidence of berry sunburn, with a negative effect on the biosynthesis of anthocyanins. On the other hand, leaf removal applied before blooming (early defoliation) positively influences berry composition by altering the source-to-sink ratio, cluster compactness, and fruit exposure prevents clusters from experiencing solar overexposure [17]. Possible negative effects of leaf removal are reduction in leaf area per vine and decrease in bud fruitfulness in the following season. Another negative effect reported in the literature is a decrease in berry weight and at the same time of titratable acidity due to a decrease in malic acid content. However, basal shoot leaf removal can increase polyphenols and anthocyanins up to $18 \%$ 
versus control vines due to better UV radiation in the cluster zone that may favourably affect phenol synthesis by stressing the berry skin; in addition, early leaf removal stabilizes wine (vine) polyphenol content $[17,20,22]$.

Aglianico is an autochthonous late season red grape variety (with a harvest period from the end of October to the first week of November) widely grown in warm, arid regions of Southern Italy such as Apulia, Campania, and Basilicata [23]. Leaf removal from Aglianico vines at veràison time alone or in association with $40 \%$ bunch thinning had no influence on the maturity parameters, except for a moderate increment in total and extractable anthocyanins [24]. In another study, two different intensities of trimming or defoliation from Aglianico vines at harvest caused a decrease in berry total soluble solids and alcohol content in the related wine [25].

The aim of the present study was to compare the effect of manual early basal leaf removal on yield, chemical composition, and anthocyanin profile of berry of Aglianico vines in the Mediterranean environment. Three basal leaf removal treatments were applied on the fruit-zone at three different sides of the canopy. The investigation was carried out for three seasons on vines trained to vertical shoot position system (VSP).

\section{Materials and Methods}

\subsection{Experimental Site and Grapevine Measurements}

The research study was carried out in 2016-2017-2018 vintages on a ten-year-old commercial vineyard located in the Castel del Monte controlled and guaranteed designation of origin (CGDO) wine area (Apulia region, Southern Italy, near Corato, $41^{\circ} 04^{\prime} 35^{\prime \prime} \mathrm{N} ; 16^{\circ} 21^{\prime} 46^{\prime \prime} \mathrm{E} 354 \mathrm{~m}$ a.s.l.). Aglianico vines, (clone VCR 14) grafted onto SO4 clone ISV VCR 4 (Vitis berlandieri $\times$ Vitis riparia) rootstock, were planted in east-west oriented rows with a spacing of $0.8 \mathrm{~m}$ between vines and $2.3 \mathrm{~m}$ between rows, (5435 vines per hectare) trained to vertical shoot positioned (VSP) system. In the area of Castel del Monte, the prevailing rows orientation is north-south, but many winegrowers, for some years, have been testing the effects of the east-west orientation on autochthonous varieties over large areas. The vines were pruned to a single Guyot system (one cane pruned with 10 buds and one spur pruned to two buds) with 12 buds per vine. Cane was positioned at $0.80 \mathrm{~m}$ above the soil; two couples of wires were utilized to maintain the vertical shoot position and their heights above the canes were $0.30 \mathrm{~m}$ and $0.70 \mathrm{~m}$, respectively. Canopy management practices included vertical shoot positioning in the month of June, followed by mechanical hedging when shoots were $30 \mathrm{~cm}$ above the top catch wire, with a total canopy height of $130 \mathrm{~cm}$.

The average climate of the area is "Mediterranean", with the coldest month mean temperature in January $\left(8^{\circ} \mathrm{C}\right)$, and the hottest one in August $\left(27^{\circ} \mathrm{C}\right)$ and mean annual rainfall is $500 \mathrm{~mm}$, and mostly concentrated from September to April. The vineyard drip irrigation system was a pressurized, filtered system with a single irrigation line per row and pressure-compensated emitters, with a discharge rate of $4 \mathrm{Lh}^{-1}$.

Approximately 15 days before flowering (mid of May, BBCH 57), the following basal leaf removal treatments (all leaves removed from the base of shoot to the node just above the apical cluster) were manually performed:

- $\mathrm{N}: 100 \%$ of fruit-zone leaves were removed from the north canopy side (bunches exposed to the afternoon sun);

- S: $100 \%$ of fruit-zone leaves were removed from the south canopy side (bunches exposed to the morning sun;

- N-S: $100 \%$ of fruit-zone leaves were removed from the north and the south sides of the canopy (bunches exposed to the morning and afternoon sun), respectively;

- A control thesis (non-defoliated vines, where all basal leaves were retained in each shoot) was used for comparison. 
Six adjacent rows were selected to set up a randomized complete block design, with two rows as a block. Within each two rows, three sections of 18 vines per plot were tagged and randomly assigned to the leaf removal treatments imposed with 54 vines for each treatment. All vines were subjected to the same vineyard management practices and irrigation supplied about $800 \mathrm{~m}^{3} \mathrm{ha}^{-1}$ of water including the rainfall amount, from July to early September, by a drip irrigation system each year. Weather data were recorded during the experiment by an automatic weather station (iMETOS 3.3, Pessl Instruments GmbH, Weiz, Austria) located approximately $20 \mathrm{~m}$ from the experimental vineyard while historical data sources were provided from Compartimento di Bari del Servizio Idrografico e Mareografico Nazionale (S.I.M.N).

\subsection{Yield Components and Grape Composition}

Harvest (approximately $50 \mathrm{~kg}$ of grapes obtained per treatment replication) was performed manually at the end of October; clusters for each vine were counted and weighed for calculation of total vine yield. Total soluble solids ( ${ }^{\circ}$ Brix) were determined on fresh grape juice extracted from 300 berry samples randomly collected from each replicate with the use of a digital refractometer (Atago Co Ltd., Tokyo, Japan). Titratable acidity, expressed as $\mathrm{g} \mathrm{L}^{-1}$ of tartaric acid equivalent by titration with $0.1 \mathrm{~N}$ $\mathrm{NaOH}$, was measured with an auto-titrator to an end pH of 7.0 (EEC 2676 standard procedure [26]), whereas juice $\mathrm{pH}$ was measured using a pH meter (Crison Basic 20, Crison Instruments, Alella, Spain). Additionally, about $100 \mathrm{~kg}$ of grapes from each treatment was used for winemaking according to a specific protocol with spontaneous malolactic fermentation [23]. Wine data are not presented in this paper.

\subsection{Phenols Extraction}

From each replicate, 100 berries were collected in a plastic bag and stored at $-20^{\circ} \mathrm{C}$ until analysis. The extraction of phenols from grape skins was performed using 30 berries (three replicates for each sample) according to the method of Di Stefano and Cravero [27] with some modifications. Briefly, the skins were manually removed from the pulp and then macerated in $75 \mathrm{~mL}$ of ethanol/water/HCl solution $(70 / 30 / 1 v / v)$ for $24 \mathrm{~h}$ in the dark at room temperature. The extract was then filtered through filter paper and submitted to the analysis of the phenolic composition, antioxidant activity and anthocyanin composition.

\subsection{Phenols and Antioxidant Activity Analysis}

Flavonoids $(\mathrm{F})$, anthocyanins (A), flavans reactive with vanillin (FRV), proanthocyanidins $(\mathrm{P})$ and total polyphenols (TP) were determined according to Gambacorta et al. [7] using an UV-visible spectrophotometer (Beckman Coulter DU 800, Brea, CA, USA). Antioxidant activity (AA) was assessed by 2,2'-azino-bis (3-ethylbenzothiazoline-6-sulfonic acid) (ABTS) assay as reported by Trani et al. [28] using an Evolution 60S UV-visible spectrophotometer (ThermoFisher Scientific, Rodano, Italy). The results are expressed as $\mathrm{mmol} \mathrm{L}^{-1}$ Trolox equivalent antioxidant capacity (TEAC) [29-31]

\subsection{HPLC-DAD Anthocyanin Analysis}

Analysis of anthocyanin compounds was performed by HPLC using a Waters $600 \mathrm{E}$ apparatus (Waters, Milford, MA, USA) that included a quaternary pump, a photodiode array detector (DAD) and an injection valve with a $20 \mu \mathrm{L}$ loop. The samples, previously filtered on a $0.45 \mu \mathrm{m}$ nylon membrane, were injected into a NovaPack C18 $(150 \times 3.9 \mathrm{~mm}, 4 \mu \mathrm{m}$ particle size, Waters $)$ column maintained at $30{ }^{\circ} \mathrm{C}$ and eluted at a $1 \mathrm{~mL} \mathrm{~min}^{-1}$ flow rate with $10 \%$ formic acid (solvent $\mathrm{A}$ ), and acetonitrile (solvent B). The gradient program of solvent A was as follows: 0-1 min 95\%, 1-22 $\mathrm{min} 60 \%, 22-23 \mathrm{~min}$ $30 \%, 23-28 \mathrm{~min} 30 \%, 28-28.1 \mathrm{~min} 95 \%$. Detection was performed at $520 \mathrm{~nm}$, and quantitative analysis was performed according to an external standard method based on a calibration curve obtained by injection of solutions at different concentrations of malvidin-3-O-glucoside $\left(R^{2}=0.9993\right)$. Tentative identification of anthocyanins was achieved by combining the elution patterns and data reported by Revilla and Ryan [32]. Results are expressed as mg of malvidin-3-glucoside equivalents per $\mathrm{kg}$ of grape. 


\subsection{Statistical Analysis}

Chemical analyses were repeated three times for each sample. The multivariate analysis of variance (MANOVA) and the single ANOVA were performed by means of the OriginPro 2018b software (OriginLab, Northampton, MA, USA) in order to evaluate the effects of season (S) and leaf removal (LR) and their interaction. Many interactions between $S$ and LR were observed but only those regarding phenol compounds and the most relevant anthocyanins assessed by high performance liquid chromatography, (Dp, delphinidin-3-glucoside; $\mathrm{Cy}$, cyanidin-3-glucoside; $\mathrm{Pt}$, petunidin-3-glucoside; $\mathrm{Pn}$, peonidin-3-glucoside; Mv, malvidin-3-glucoside; TA, total anthocyanins) were discussed.

\section{Results and Discussion}

\subsection{Growing Season Environmental Conditions and Grape Yields}

The average microclimate conditions (30 years) of the vineyard site are Mediterranean semi-arid conditions, with an annual mean temperature of $16.3^{\circ} \mathrm{C}$ (maximum mean temperature $38.7^{\circ} \mathrm{C}$ in August, minimum mean temperature $-2.3^{\circ} \mathrm{C}$ in February) and mean annual rainfall of $563 \mathrm{~mm}$ (Table 1). During the experimental seasons, the rainfall amounts from budbreak (April) to harvest (October) were 445, 128 and $306 \mathrm{~mm}$ in 2016, 2017 and 2018, respectively. In 2016, rainfall in spring was much higher compared to 2017, and this delayed harvest. During berry ripening (from July to August), the average maximum air temperatures were $39.3{ }^{\circ} \mathrm{C}$ in $2016,41.2{ }^{\circ} \mathrm{C}$ in 2017 and $36.4{ }^{\circ} \mathrm{C}$ in 2018. The highest accumulated growing degree day (GDD) was observed in 2017, the lowest in 2016. In all years, the number of days with maximum temperatures exceeding $35^{\circ} \mathrm{C}$ was more than the average; nevertheless, the daily average total direct solar radiation was in line with the 30 year site average. Seasonal reference evapotranspiration $\left(\mathrm{ET}_{\mathrm{r}}\right)$ was similar to the site average in the first and third years, but higher than average in the second year (Table 1).

Table 1. Weather conditions measured at the vineyard weather station.

\begin{tabular}{|c|c|c|c|c|c|c|c|}
\hline \multirow[t]{2}{*}{ Parameters } & \multirow[t]{2}{*}{ Average 1970-2000 } & \multicolumn{3}{|c|}{ Annual } & \multicolumn{3}{|c|}{$\begin{array}{l}\text { From Bud Break to Harvest } \\
\text { (1 April to } 31 \text { October) }\end{array}$} \\
\hline & & 2016 & 2017 & 2018 & 2016 & 2017 & 2018 \\
\hline Mean annual $\mathrm{T}\left({ }^{\circ} \mathrm{C}\right)$ & 16.3 & 16.0 & 16.2 & 16.4 & 20.4 & 21.3 & 21.3 \\
\hline Min mean $\mathrm{T}\left({ }^{\circ} \mathrm{C}\right)$ & -2.3 & -3.8 & -6.3 & -6.7 & 3.8 & 2.8 & 5.0 \\
\hline Max mean $\mathrm{T}\left({ }^{\circ} \mathrm{C}\right)$ & 38.7 & $24.7^{+}$ & $22.8^{+}$ & $22.7^{\dagger}$ & 40.4 & 44.2 & 39.9 \\
\hline Rainfall (mm) & 563 & 669 & 349 & 633 & 455 & 128 & 306 \\
\hline Accumulated GDD $\left({ }^{\circ} \mathrm{C}\right)$ & 2330 & - & - & - & 2078 & 2311 & 2276 \\
\hline Days daily max. $\mathrm{T}>35^{\circ} \mathrm{C}$ & 7 & - & - & - & 8 & 34 & 9 \\
\hline $\mathrm{ET}_{\mathrm{r}}(\mathrm{mm})$ & 1063 & 1016 & 1187 & 1059 & 833 & 959 & 840 \\
\hline
\end{tabular}

${ }^{+}$from January to April; GDD: growing degree days (calculated from daily maximum and minimum temperature with no upper limit and a base temperature of $10{ }^{\circ} \mathrm{C} ; \mathrm{ET}_{\mathrm{r}}$ : reference evapotranspiration.

Leaf removal treatment removed an average of $0.62 \mathrm{~m}^{2}$ leaf area per vine in the north side of the canopy, $0.59 \mathrm{~m}^{2}$ leaf area per vine in the south side of the canopy and $0.98 \mathrm{~m}^{2}$ leaf area per vine in the north-south side of the canopy, reducing the total leaf area per vine compared with the control vine by 34, 35 and 39\%, respectively. Grape yield data are reported in Table 2. Leaf removal did not affect vine yield, cluster weight and cluster number per vine. Statistical analysis did not reveal any season $\times$ treatment interactions $\left(S^{*} L R\right)$ on cluster number, berry mass and yield per vine, whereas the season significantly affected leaf area per vine. The effect of $S^{*} L R$ was observed on cluster weight and leaf area per vine. Obviously, the early basal leaf removal (pre-bloom leaf removal) caused a decrease in leaf area from control vines to N-S treatment and consequently affected the leaf area to fruits weight ratio, which ranged from 1.16 to $0.60 \mathrm{~m}^{2} / \mathrm{kg}$, respectively (data not shown). Partial defoliation of vines improved the canopy microclimate and photosynthetic efficiency of remaining leaves because only the older ones with low photosynthetic potential are removed [33,34]. 
Table 2. Effects of season and leaf removal treatment on yield components of Aglianico.

\begin{tabular}{ccccc}
\hline Source of Variation & Cluster Number & Cluster Weight (g) & Yield (kg/vine) & $\begin{array}{c}\text { Leaf Area per Vine } \\
\left(\mathbf{m}^{2} / \text { vine }\right)\end{array}$ \\
\hline Season (S) & & & & \\
2016 & 26.38 & 172.74 & 4.56 & 3.75 \\
2017 & 25.86 & 177.21 & 4.30 & 3.50 \\
2018 & 26.42 & 162.16 & 4.26 & 3.65 \\
Significance & $\mathrm{ns}$ & $\mathrm{ns}$ & $\mathrm{ns}$ & $\mathrm{ns}$ \\
Leaf removal (LR) & & & 4.08 & $4.75 \mathrm{a}$ \\
Control & 24.25 & 172.86 & 4.09 & $3.12 \mathrm{c}$ \\
North & 26.39 & 154.98 & 4.52 & $3.76 \mathrm{~b}$ \\
South & 28.50 & 160.51 & 4.89 & $2.90 \mathrm{c}$ \\
North-South & 25.61 & 166.56 & $\mathrm{~ns}$ & $* * *$ \\
Significance & $\mathrm{ns}$ & $\mathrm{ns}$ & $\mathrm{ns}$ & $*$ \\
Interaction & $\mathrm{n}$ & $*$ & $\mathrm{~ns}$ \\
S*LR & $\mathrm{ns}$ &
\end{tabular}

In column, data followed by different letters indicate statistically significant differences at $p<0.05$. Significance: $\mathrm{ns}^{*}$,

${ }^{* *}$ and ${ }^{* * *}$, not significant or significant at $p \leq 0.05, p \leq 0.01$ or $p \leq 0.001$, respectively.

\subsection{Berry Composition}

Table 3 shows the effect of season and leaf removal on the gross composition of grapes. Season exerted a greater effect than leaf removal on all chemical and phenolic parameters. The 2017 season, characterized by warm climate and lowest rainfall from bud break to harvest, induced the best ripening grade. In fact, total soluble solid (TSS) concentration was about 10\% higher than in 2016 and 2018; however, the grapes exhibited optimal values of $\mathrm{pH}$ and titratable acidity (TA). The same $\mathrm{pH}$ and TA values were recorded in the first two years of experimentation, whereas the highest $\mathrm{pH}$ and the lowest TA values were detected in 2018, very close to those found in a previous research study carried out on Aglianico in a nearby area [7]. Concerning phenols, the 2017 season promoted the highest accumulation of flavonoids (F), anthocyanins (A), flavans reactive with vanillin (FRV) and proanthocyanidins $(\mathrm{P})(p<0.001)$. Consequently, grapes had the highest values of total polyphenols (TP) and antioxidant activity (AA); these two parameters are interdependent, even though AA also depends on the chemical structure of each phenolic compound [29]. Grape quality was slightly affected by the defoliation treatment. Total soluble solids in berries of defoliated vines were similar, or just the same, as those of non-defoliated vines, despite much lower leaf areas [19].

Table 3. Chemical and phenolic characteristics of Aglianico grapes as a function of season and leaf removal.

\begin{tabular}{|c|c|c|c|c|c|c|c|c|c|c|}
\hline $\begin{array}{l}\text { Source of } \\
\text { Variation }\end{array}$ & $\begin{array}{l}\text { Total Soluble } \\
\text { Solids (Brix) }\end{array}$ & $\mathrm{pH}$ & $\begin{array}{c}\text { Titratable } \\
\text { Acidity } \\
\text { (g/L) }\end{array}$ & $\begin{array}{l}\text { Flavonoids } \\
(\mathrm{mg} / \mathrm{kg})\end{array}$ & $\begin{array}{l}\text { Anthocyanins } \\
(\mathrm{mg} / \mathrm{kg})\end{array}$ & $\begin{array}{l}\text { FRV } \\
(\mathrm{mg} / \mathrm{kg})\end{array}$ & $\begin{array}{l}\text { Proantocyanidins } \\
(\mathrm{mg} / \mathrm{kg})\end{array}$ & FRV/P & $\begin{array}{c}\text { TP } \\
(\mathrm{mg} / \mathrm{kg})\end{array}$ & $\begin{array}{c}\text { Antioxidant } \\
\text { Activity } \\
\text { (mmol/kg) }\end{array}$ \\
\hline \multicolumn{11}{|l|}{ Season (S) } \\
\hline 2017 & $25.43 a$ & $3.14 \mathrm{~b}$ & $7.45 a$ & $4716 a$ & $3098 a$ & $1271 \mathrm{a}$ & $2282 a$ & $0.55 \mathrm{a}$ & 4141a & $19.70 a$ \\
\hline 2018 & $23.58 \mathrm{~b}$ & $3.30 \mathrm{a}$ & $5.27 \mathrm{~b}$ & $2530 c$ & $1600 \mathrm{~b}$ & $691 \mathrm{c}$ & $1834 \mathrm{~b}$ & $0.38 \mathrm{~b}$ & $2009 c$ & $10.76 \mathrm{~b}$ \\
\hline Significance & $* * *$ & $* * *$ & $* * *$ & $* * *$ & $* * *$ & $* * *$ & $* * *$ & $* * *$ & $* * *$ & $* * *$ \\
\hline \multicolumn{11}{|l|}{ Leaf removal } \\
\hline South & 24.59 & 3.22 & 6.31 & 3474 & 2139 & $927 \mathrm{~b}$ & $2047 a$ & $0.45 \mathrm{~b}$ & $3122 a$ & $15.24 a$ \\
\hline North-South & 23.95 & 3.18 & 6.63 & 3335 & 2160 & $1084 a$ & $2074 a$ & $0.51 \mathrm{a}$ & $2891 \mathrm{ab}$ & $13.26 \mathrm{ab}$ \\
\hline Significance & ns & ns & ns & $\mathrm{ns}$ & $\mathrm{ns}$ & $* * *$ & $* * *$ & $*$ & $* * *$ & $* * *$ \\
\hline \multicolumn{11}{|l|}{ Interaction } \\
\hline$S^{*} \mathrm{LR}$ & ns & ns & ns & ** & $* * *$ & $* * *$ & $* * *$ & $* * *$ & $* * *$ & $* * *$ \\
\hline
\end{tabular}

Titratable acidity: as tartaric acid; flavonoids: as (+)-catechin; anthocyanins: as malvidin-3-glucoside; FRV, flavans reagent with vanillin: as (+)-catechin; proanthocyanidins: as cyanidin chloride; TP, total polyphenols: as gallic acid. ${ }^{\dagger}$ In columns, data followed by different letters indicate statistically significant differences at $p<0.05$. Significance: $\mathrm{ns},{ }^{*}, * *$ and ${ }^{* * *}$, not significant or significant at $p \leq 0.05, p \leq 0.01$, or $p \leq 0.001$, respectively.

Additionally, titratable acidity was not influenced by the treatments, suggesting that early leaf removal is meaningful for wine production in warm regions where the grape total acidity is commonly low $[1,3]$. No influence on flavonoids and anthocyanins content was observed, whereas an impact on FRV, 
$\mathrm{P}, \mathrm{FRV} / \mathrm{P}, \mathrm{TP}$, and AA was observed as a function of the canopy side; an increase was observed at the south and north-south canopy side, in accordance with other studies [35]. This was a consequence of increased cluster temperature and improved fruit-zone light conditions caused by the decrease in leaf area (in this study, it was a moderate defoliation). In detail, removal at the south canopy sides caused a statistically significant increase in $\mathrm{P}, \mathrm{TP}$ and AA $(+12,+16$ and $+13 \%$, respectively) and a decrease in FRV/P $(-8 \%)$, whereas removal at north-south canopy caused an increase in FRV and $\mathrm{P}(+21$ and $+14 \%$, respectively).

No interactions were observed between seasons and leaf removal for basic chemical parameters such as sugars, $\mathrm{pH}$, and total acidity. However, $\mathrm{S}^{*} \mathrm{LR}$ interactions were found for all phenolic parameters and for antioxidant activity, as shown in Figure 1.
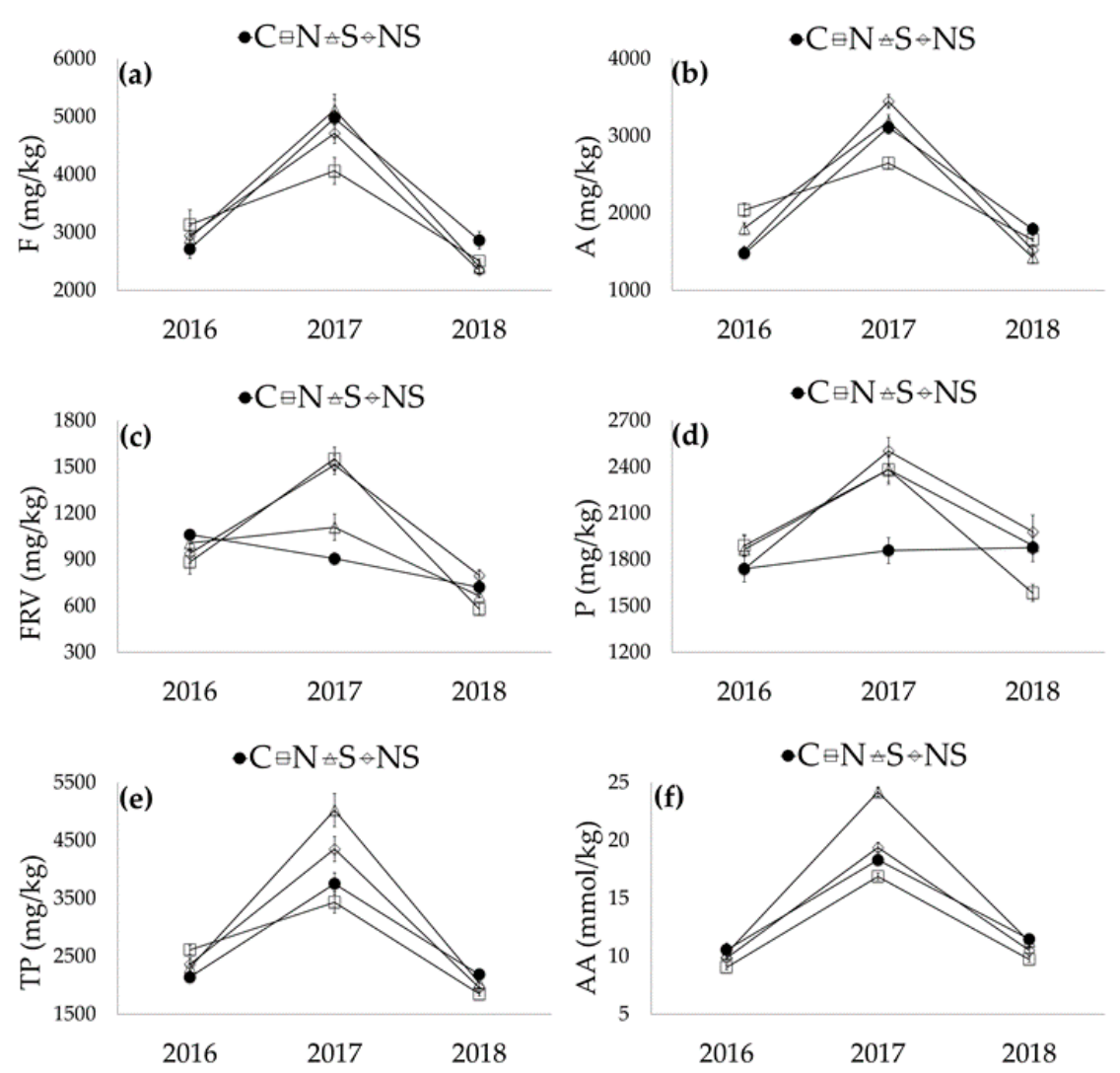

Figure 1. Interaction between season and leaf removal on phenolic parameters such as flavonoids (a), anthocyanins as malvidin-3-glucoside (b), flavans reagent with vanillin as (+)-catechin (c), proanthocyanidins as cyanidin chloride (d), total polyphenols as gallic acid (e) and antioxidant activity (f).

The interaction was similar for flavonoids (Figure 1a) and anthocyanins (Figure 1b). Leaf removal in 2016 caused an increase, whereas a decrease was found in 2018. The effect was different in 2017, when the only positive effect was observed for anthocyanins at the north-south side, due to both the higher level of defoliation (on two sides) and warmer climate (air temperature and number of days (34) with daily maximum temperature exceeding $35^{\circ} \mathrm{C}$ ). Concerning flavans reactive with vanillin, leaf removal caused a decrease in 2016 and increase in 2017, especially when leaves were removed from the north and north-south canopy side (Figure 1c). The impact on proanthocyanins was different, they increased in all years, except when leaf removal was applied at the north side in 2018 (Figure 1d). As for total polyphenols, the concentration increased in 2016 and decreased in 2018 (Figure 1e), whereas in 2017 an increase was only found for leaf removal at south and north-south sides. Finally, a decrease in antioxidant activity was found in 2016 and 2018 and an increase in 2017, except when leaf removal was applied at the north side (Figure 1f). 


\subsection{Anthocyanin Profile}

Free and bound anthocyanins are directly responsible for the berry skin colour of red varieties [36]. Figure 2 shows the anthocyanin profile of Aglianico grape skin extract. Fourteen compounds were identified and quantified, among which the most abundant were malvidin-3-O-glucoside and transmalvidin-3-coumaroyl-glucoside.

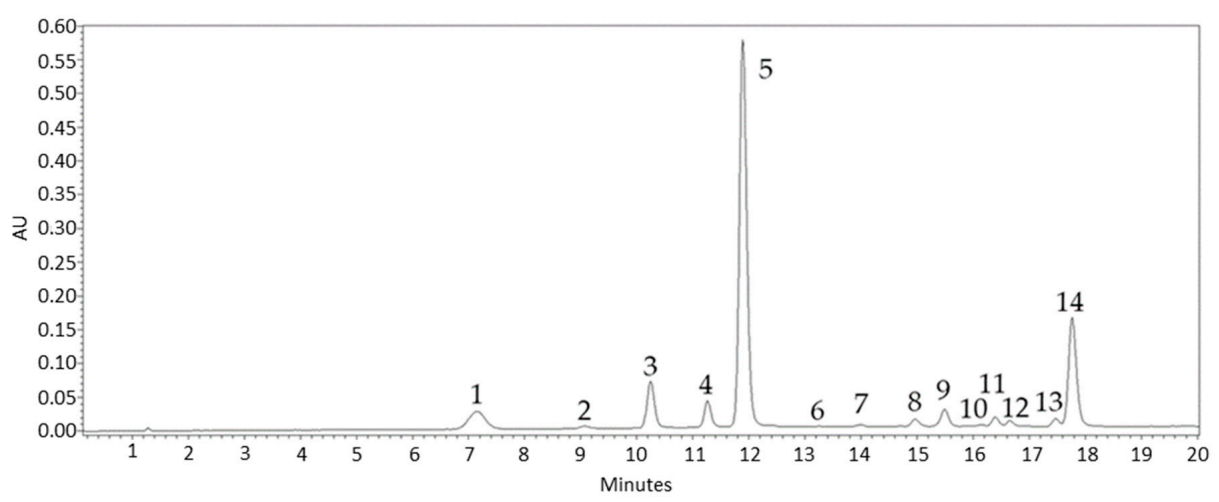

Figure 2. HPLC-photodiode array detector (DAD) chromatogram of skin extract of Aglianico grapes recorded at $520 \mathrm{~nm}$. (1) Dp, delphinidin-3-glucoside; (2) Cy, cyanidin-3-glucoside; (3) Pt, petunidin-3-glucoside; (4) Pn, peonidin-3-glucoside; (5) Mv, malvidin-3-glucoside; (6) Dp-Ac, delphinidin-3-acetyl-glucoside; (7) Pt-Ac, petunidin-3-acetyl-glucoside; (8) Pn-Ac, peonidin-3-acetyl-glucoside; (9) Mv-Ac, malvidin-3-acetyl-glucoside; (10) c-Mv-Cm, cis-malvidin-3-coumaryl-glucoside; (11) Mv-Cf, malvidin-3-caffeoyl-glucoside; (12) Pt-Cm, petunidin-3-coumaroyl-glucoside; (13) Pt-Cm, petunidin-3-coumaroyl-glucoside; (14) $t$-Mv-Cm, transmalvidin-3-coumaroyl-glucoside.

Table 4 summarizes the effects of season and leaf removal on the anthocyanin composition and concentration.

The season exerted a strong effect on content; in 2017, it was about double that in 2016 and 2018 due to the climatic conditions, characterized by the greatest temperature excursion and less rainfall. The content found in 2017 season was close to those reported in Aglianico vines grown in the countryside of Minervino Murge in 2007 and 2008 [7]. The impact on composition was less relevant than that on concentration. It is worth highlighting that the anthocyanin proportions in the three years under study were similar to those reported in literature for the same variety grown in nearby areas of the Apulia region in different years [7,31,32]. In this study, 2017 grapes were characterized by the highest percentages of non-acylated anthocyanins $(82.5 \%$ ) and the lowest of acylated forms ( 5.3 and $14.5 \%$ for acetylated and coumaroylated, respectively). In 2016 and 2018, the grapes had similar anthocyanin content but different proportion of anthocyanin compounds; in 2018 non-acetylated forms were lower ( 67.9 vs. $74.8 \%)$ and coumaroylated forms ( 23.7 vs. $17.0 \%$ ) were more represented. Leaf removal increased the content of anthocyanins ( $+6 \%$ for north and $+20 \%$ for south and north-south, respectively), but poorly influenced the composition. In fact, the percentages of non-acylated forms were 75.1, 76.3 and $77.6 \%$ (S, NS and N, respectively) versus $77.3 \%$ in control vines; acetylated forms were 5.5 (NS) and $5.9 \%$ (N and S) versus 5.6\% in control; coumaroylated forms were 17.0, 17.8 and $19.5 \%$ (NS, N and S, respectively) versus $20 \%$ in control. On the whole, the concentration of total anthocyanins increased in the defoliated vines, confirming that the synthesis of these compounds, which has a genetic basis, is significantly affected by leaf removal. In addition, leaf removal also exerted some effect on the anthocyanin profile, due to changes in the exposition of berries to the temperature, UV, and sunlight, which altered the partitioning between the various forms of anthocyanins [37]. In particular, all free anthocyanins increased in all leaf removal treatments except for malvidin-3-glucoside, which decreased for north canopy side leaf removal. As to the $S^{*} L R$ interactions, significant differences were found for all anthocyanins, except for Pt-Cm. Figure 3 shows the $S^{*} \mathrm{LR}$ interactions of non-acylated and total anthocyanins. 
Table 4. Anthocyanin composition of Aglianico grapes as a function of season and leaf removal (mg/kg as malvidin-3-glucoside).

\begin{tabular}{|c|c|c|c|c|c|c|c|c|c|c|c|c|c|c|c|}
\hline $\begin{array}{l}\text { Source of } \\
\text { Variation }\end{array}$ & Dp & Cy & $\mathrm{Pt}$ & Pn & Mv & Dp-Ac & Pt-Ac & Pn-Ac & Mv-Ac & $c-\mathrm{Mv}-\mathrm{Cm}$ & $\mathrm{Mv}-\mathrm{Cf}$ & $\mathrm{Pt}-\mathrm{Cm}$ & $\mathrm{Pn}-\mathrm{Cm}$ & $t-\mathrm{Mv}-\mathrm{Cm}$ & $\begin{array}{c}\text { Total } \\
\text { Anthocyanins }\end{array}$ \\
\hline \multicolumn{16}{|l|}{ Season (S) } \\
\hline 2016 & $76.1 \mathrm{~b}$ & $5.0 \mathrm{~b}$ & $84.1 \mathrm{~b}$ & $39.9 \mathrm{~b}$ & $617.7 \mathrm{~b}$ & $3.1 \mathrm{~b}$ & $13.5 \mathrm{a}$ & $19.5 \mathrm{~b}$ & $31.3 \mathrm{~b}$ & $1.1 \mathrm{~b}$ & $13.7 \mathrm{~b}$ & $6.9 \mathrm{c}$ & $12.6 \mathrm{~b}$ & $178.7 \mathrm{~b}$ & $1098.8 \mathrm{~b}$ \\
\hline 2017 & $177.5 \mathrm{a}$ & $11.8 \mathrm{a}$ & $190.6 \mathrm{a}$ & $72.8 \mathrm{a}$ & $1208.6 \mathrm{a}$ & $7.8 \mathrm{a}$ & $13.6 \mathrm{a}$ & $27.0 \mathrm{a}$ & $58.3 \mathrm{a}$ & $1.6 \mathrm{a}$ & $29.2 \mathrm{a}$ & 11.1a & $18.6 \mathrm{a}$ & 281.6a & 2019.0a \\
\hline 2018 & $55.5 \mathrm{~b}$ & $3.3 \mathrm{~b}$ & $62.0 \mathrm{~b}$ & $28.8 \mathrm{~b}$ & $619.6 \mathrm{~b}$ & $2.7 \mathrm{~b}$ & $4.5 \mathrm{~b}$ & $13.3 \mathrm{~b}$ & $48.9 a$ & $1.5 \mathrm{a}$ & $15.0 \mathrm{~b}$ & $9.1 \mathrm{~b}$ & $11.1 \mathrm{~b}$ & $258.0 \mathrm{a}$ & $1133.4 \mathrm{~b}$ \\
\hline Significance & $* * *$ & $* * *$ & $* * *$ & $* * *$ & $* * *$ & $* * *$ & $* * *$ & $* * *$ & $* * * *$ & $* * *$ & $* * *$ & $* * *$ & $* * * *$ & $* * *$ & $* * *$ \\
\hline \multicolumn{16}{|l|}{ Leaf removal } \\
\hline Control & $64.4 \mathrm{~b}$ & $4.8 \mathrm{~b}$ & $83.6 \mathrm{~b}$ & $39.7 \mathrm{~b}$ & $784.9 \mathrm{~b}$ & $4.3 \mathrm{~b}$ & $9.3 \mathrm{c}$ & $15.1 \mathrm{~b}$ & $42.4 \mathrm{~b}$ & $1.6 \mathrm{a}$ & $16.4 \mathrm{c}$ & 8.9 & $12.4 \mathrm{~b}$ & $234.1 \mathrm{~b}$ & $1264.0 \mathrm{c}$ \\
\hline North & $112.9 \mathrm{a}$ & $7.9 a$ & $121.2 \mathrm{a}$ & $53.6 \mathrm{a}$ & $770.2 \mathrm{~b}$ & $4.4 \mathrm{~b}$ & $10.4 \mathrm{~b}$ & $22.6 \mathrm{a}$ & $43.5 \mathrm{~b}$ & $1.4 \mathrm{ab}$ & $18.0 \mathrm{~b}$ & 8.9 & $16.9 \mathrm{a}$ & $217.8 \mathrm{~b}$ & $1373.7 \mathrm{~b}$ \\
\hline South & $110.2 a$ & $6.2 \mathrm{ab}$ & $120.3 a$ & $43.5 \mathrm{~b}$ & $863.8 \mathrm{a}$ & $4.4 \mathrm{~b}$ & $12.0 \mathrm{a}$ & $22.2 \mathrm{a}$ & $51.3 \mathrm{a}$ & $1.2 \mathrm{~b}$ & $22.1 \mathrm{a}$ & 9.1 & $13.5 \mathrm{~b}$ & $273.8 \mathrm{a}$ & $1523.0 \mathrm{a}$ \\
\hline North-South & $124.6 \mathrm{a}$ & $7.8 \mathrm{a}$ & $123.9 a$ & $51.7 \mathrm{a}$ & $842.4 a$ & $5.0 \mathrm{a}$ & $10.4 \mathrm{~b}$ & $19.8 \mathrm{a}$ & $47.4 a$ & 1.4ab & $20.7 \mathrm{a}$ & 9.3 & $13.5 \mathrm{~b}$ & $232.1 \mathrm{~b}$ & $1507.5 \mathrm{a}$ \\
\hline Significance & $* * * *$ & $* * *$ & $* * *$ & $* *$ & $\stackrel{*}{*}$ & $*$ & $* * * *$ & $* * * a$ & 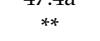 & $* * *$ & $* *$ & ns & $* * *$ & $x_{* *}^{20.10}$ & $* * *$ \\
\hline Interaction & & & & & & & & & & & & & & & \\
\hline$S^{*} \mathrm{LR}$ & $* * *$ & $* * *$ & $* * *$ & $* * *$ & $* * *$ & $* * *$ & ** & $* * *$ & $* *$ & $* * *$ & ** & ns & $* * *$ & $* *$ & $* * *$ \\
\hline
\end{tabular}

In columns, data followed by different letters indicate statistically significant differences at $p<0.05$. Dp, delphinidin-3-glucoside; Cy, cyanidin-3-glucoside; Pt, petunidin-3glucoside; Pn, peonidin-3-glucoside; Mv, malvidin-3-glucoside; Dp-Ac, delphinidin-3-acetyl-glucoside; Pt-Ac, petunidin-3-acetyl-glucoside; Pn-Ac, peonidin-3-acetyl-glucoside; $\mathrm{Mv}-\mathrm{Ac}$, malvidin-3-acetyl-glucoside; $c$-Mv-Cm, cis-malvidin-3-coumaryl-glucoside; $\mathrm{Mv}-\mathrm{Cf}$, malvidin-3-caffeoyl-glucoside; Pt-Cm, petunidin-3-coumaroyl-glucoside; $t$-Mv-Cm, trans-malvidin-3-coumaroyl-glucoside. Significance: $\mathrm{ns}^{*}{ }^{*}, * *$ and ${ }^{* * *}$, not significant or significant at $p \leq 0.05, p \leq 0.01$, or $p \leq 0.001$, respectively. 

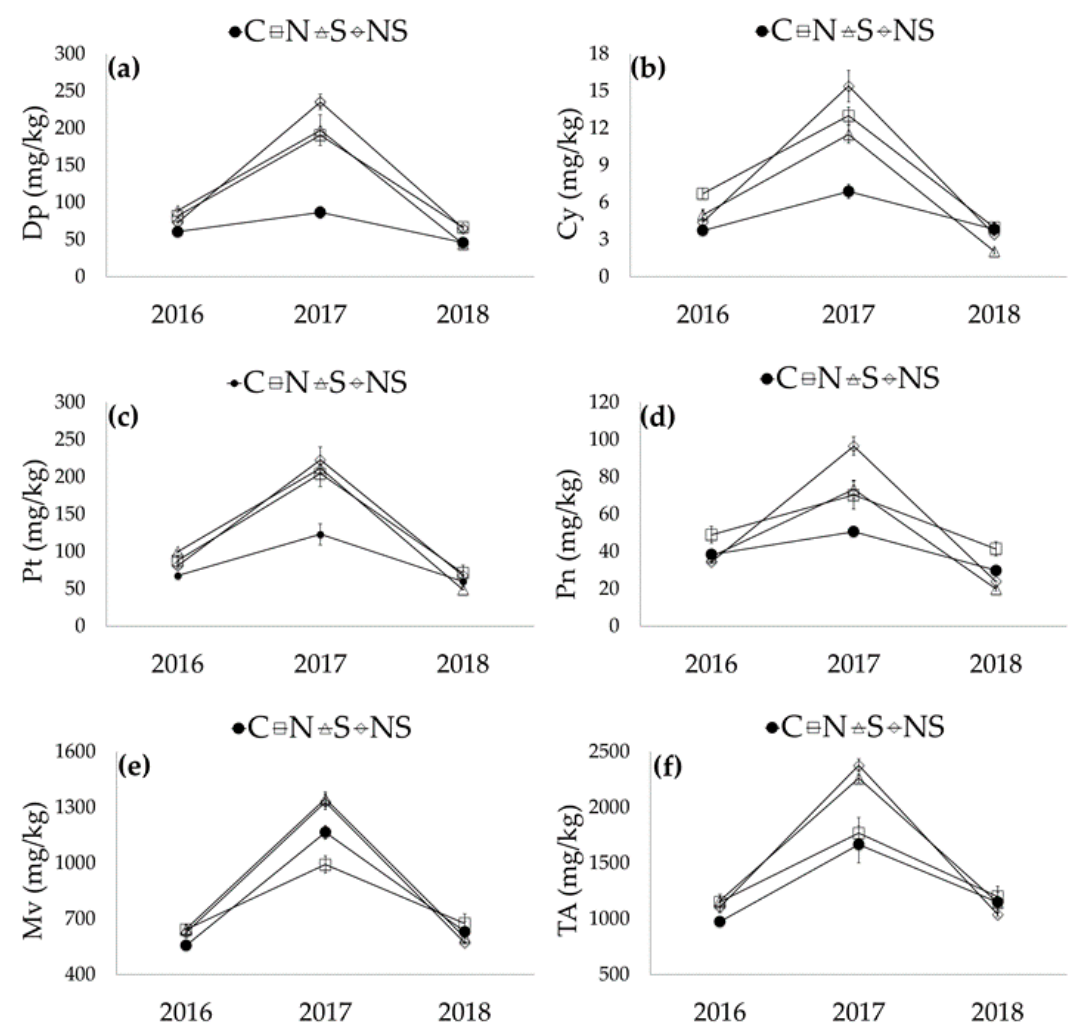

Figure 3. Interaction between season and leaf removal on main anthocyanins such as delphinidin-3glucoside (a), cyanidin-3-glucoside (b), petunidin-3-glucoside (c), peonidin-3-glucoside (d), malvidin-3glucoside (e) and total anthocyanins (f).

In comparison to control, leaf removal always led to significant increase in Dp, except for 2018 at the south side (Figure 3a). The treatment had positive effect on Cy in 2016 and 2017 and negative in 2018, especially for defoliation at the south side (Figure 3b). Pt behaved similarly to Cy (Figure 3c), whereas Pn increased in 2017 and decreased in 2016 and 2018 at the south and north-south canopy side (Figure $3 \mathrm{~d}$ ). In regard to $\mathrm{Mv}, \mathrm{LR} * \mathrm{~S}$ was very different and much more complex; this anthocyanin increased in 2016 and 2018, corresponding to treatment at the north side, and decreased in 2017. When defoliation was performed at the south and north-south sides, it increased in 2016 and 2017 and decreased in 2018 (Figure 3e). Finally, total anthocyanins increased in 2016 and 2017 seasons, but the effect in 2018 was negligible (Figure 3f).

\section{Conclusions}

The results of this study indicate that the effect of early leaf removal on Aglianico grape quality is strongly related with the canopy side of defoliation, season (year) and intensity of the treatment (number of leaves removed), since all these variables affect the canopy and berry microclimate [16,33]. Additionally, the vineyard row orientation and leaf removal canopy side exert a significant role in determining grape microclimate, mainly in regard to temperature, which affects berry composition [1,2,38]. A specific research study on the effects of row orientation on microclimate changes on Syrah grapevine in the Southern Hemisphere (South Africa) has pointed out that from late morning to afternoon, the light patterns of the east-west (EW) orientated canopies mainly showed a dominating radiation effect on the $\mathrm{N}$ canopy side, from above, and in the apical part of the canopy. However, the EW oriented rows received the highest sunlight from above in particular, as well as from the $\mathrm{N}$ canopy side and consequently the leaves on the $\mathrm{N}$ side of the EW orientated canopies showed much higher photosynthetic activity than those on the $S$ side. In conclusion, in the Southern Hemisphere, the clusters of EW oriented rows were therefore predominantly illuminated from the $\mathrm{N}$ canopy side [38]. Another research study in the North 
Hemisphere (Greece) investigated the combined effects of row orientation and basal leaf defoliation on grape ripening of cv. Agiorgitiko. Results pointed out that north exposed clusters had the lowest anthocyanins content, probably due to lower grape exposure to sunlight while the south canopy side, which received the highest sunlight, had the highest anthocyanins content [39].

These results must be evaluated within the experimental conditions applied, with particular reference to the vineyard row orientation (east-west). In fact, it is known that in the Mediterranean area, the north exposed clusters tend to present the lowest anthocyanins content, due to lower grape exposure to sunlight than those exposed at the south side. Under these conditions, the season, either alone or in interaction with leaf removal, affected all tested parameters except cluster number and yield per vine. No evidence of negative influence of the treatment on berry soluble solids was found, which is in accordance with other researchers and suggests that the remaining leaf area was sufficient to support grape berry ripening [35]. Early leaf removal had a positive effect on the accumulation of proanthocyanidins, total polyphenols, antioxidant activity and free anthocyanins, especially when applied to the south and north-south sides. In conclusion, the data obtained indicate that leaf removal before flowering might be used on Aglianico vines as an effective strategy to improve grape total polyphenols, anthocyanins concentration and antioxidant activity. This treatment represents a sustainable alternative to manual cluster thinning as it does not reduce yield per vine and can be carried out mechanically.

Author Contributions: Conceptualization, L.T. and G.G.; formal analysis, G.M. and G.G.; investigation, L.T. and G.G.; data curation, L.T., G.M., M.F. and G.G.; writing—original draft preparation, G.M. and G.G.; writing—review and editing, L.T., M.F. and G.G. All authors have read and agreed to the published version of the manuscript.

Funding: This research received no external funding.

Acknowledgments: The authors thank the CEO of Winery Torrevento, Francesco Liantonio, for hosting our research study in your vineyards and we are grateful to enologists Leonardo Palumbo, Vincenzo Gammarota and Alessandro Basile for their valuable contributions to the research.

Conflicts of Interest: The authors declare no conflict of interest.

\section{References}

1. Bergqvist, J.; Dokoozlian, N.; Ebisuda, N. Sunlight exposure and temperature effects on berry growth and composition of Cabernet Sauvignon and Grenache in the Central San Joaquin Valley of California. Am. J. Enol. Vitic. 2001, 52, 1-7.

2. Spayd, S.E.; Tarara, J.M.; Mee, D.L.; Ferguson, J.C. Separation of sunlight and temperature effects on the composition of Vitis vinifera cv. Merlot berries. Am. J. Enol. Vitic. 2002, 53, 171-182.

3. Drappier, J.; Thibon, C.; Rabot, A.; Geny-Denis, L. Relationship between wine composition and temperature: Impact on Bordeaux wine typicity in the context of global warming. Crit. Rev. Food Sci. Nutr. 2019, 59, 14-30. [CrossRef]

4. Frioni, T.; Saracino, S.; Squeri, C.; Tombesi, S.; Palliotti, A.; Sabbatini, P.; Magnanini, E.; Poni, S. Understanding kaolin effects on grapevine leaf and whole-canopy physiology during water stress and re-watering. J. Plant Physiol. 2019, 242, 153020. [CrossRef]

5. Cubasch, U.; Wuebbles, D.; Chen, D.; Facchini, M.C.; Frame, D.; Mahowald, N.; Winther, J.G. The Physical Science Basis. In Contribution of Working Group I to the Fifth Assessment Report of the Intergovernmental Panel on Climate Change; Stocker, T.F., Qin, D., Plattenr, G.K., Tignor, M., Allen, S.K., Boschung, J., Nauels, A., Xia, Y., Bex, V., Migley, P.M., Eds.; Cambridge University Press: Cambridge, UK; New York, NY, USA, 2013; pp. 119-158. [CrossRef]

6. Prodhomme, D.; Valls-Fonayet, J.; Hévin, C.; Franc, C.; Hilbert, G.; De Revel, G.; Richard, T.; Ollat, N.; Cookson, S.J. Metabolite profiling during graft union formation reveals the reprogramming of primary metabolism and the induction of stilbene synthesis at the graft interface in grapevine. BMC Plant. Biol. 2019, 19, 599. [CrossRef] [PubMed]

7. Gambacorta, G.; Antonacci, D.; La Gatta, M.; Faccia, M.; La Gatta, B.; Pati, S.; Coletta, A.; La Notte, E. Phenolic composition of Aglianico and Nero di Troia grapes and wines as affected by cover cropping and irrigation. Ital. J. Food Sci. 2011, 23, 381-394. 
8. Baiano, A.; De Gianni, A.; Previtali, M.A.; Del Nobile, M.A.; Novello, V.; de Palma, L. Effects of defoliation on quality attributes of Nero di Troia (Vitis vinifera L.) grape and wine. Food Res. Int. 2015, 75, 260-269. [CrossRef]

9. Suriano, S.; Alba, V.; Di Gennaro, D.; Suriano, M.S.; Savino, M.; Tarricone, L. Genotype/rootstocks effect on the expression of anthocyanins and flavans in grapes and wines of Greco Nero n. (Vitis vinifera L.). Sci. Hortic. 2016, 209, 309-315. [CrossRef]

10. Tarricone, L.; Alba, V.; Di Gennaro, D.; Amendolagine, A.M.; Gentilesco, G.; Masi, G. Grape and wine quality of Vitis vinifera 'Nero di Troia' in response to moderate deficit irrigation. Acta Hortic. 2017, 1150, 485-492. [CrossRef]

11. Silvestroni, O.; Lanari, V.; Lattanzi, T.; Palliotti, A.; Vanderweide, J.; Sabbatini, P. Canopy managements strategies to control yield and grape composition of Montepulciano grapevines. Aust. J. Grape Wine Res. 2019, 25, 30-42. [CrossRef]

12. Buesa, I.; Caccavello, G.; Basile, B.; Merli, M.C.; Poni, S.; Chirivella, C.; Intrigliolo, D.S. Delaying berry ripening of Bobal and Tempranillo grapevines by late leaf removal in a semi-arid and temperate-warm climate under different water regimes. Aust. J. Grape Wine Res. 2019, 25, 70-82. [CrossRef]

13. Bubola, M.; Lukić, I.; Radeka, S.; Sivilotti, P.; Grozi, K.; Vanzo, A.; Bavcar, D.; Lisjak, K. Enhancement of Istrian Malvasia wine aroma and hydroxycinnamate composition by hand and mechanical leaf removal. J. Sci. Food Agric. 2019, 99, 904-914. [CrossRef] [PubMed]

14. Petrie, P.R.; Trought, M.C.T.; Howell, G.S.; Buchan, G. The effect of leaf removal and canopy height on whole-vine gas exchange and fruit development of Vitis vinifera L. Sauvignon blanc. Funct. Plant Biol. 2003, 30, 711-717. [CrossRef] [PubMed]

15. de Palma, L.; Tarricone, L.; Muci, G.; Limosani, P.; Savino, M.; Novello, V. Leaf removal, vine physiology and wine quality in cv Negramaro (Vitis vinifera L). In Proceedings of the 17th International Symposium GiESCO, Asti-Alba, Italy, 29 August-2 September 2011; pp. 231-234.

16. Sivilotti, P.; Herrera, J.C.; Lisjak, K.; Bašaesnik, H.; Sabbatini, P.; Peterlunger, E.; Castellarin, S.D. Impact of leaf removal, applied before and after flowering, on anthocyanin, tannin, and methoxypyrazine concentrations in 'Merlot' (Vitis vinifera L.) grapes and wines. J. Agric. Food Chem. 2016, 64, 4487-4496. [CrossRef]

17. Mosetti, D.; Herrera, J.C.; Sabbatini, P.; Green, A.; Alberti, G.; Peterlunger, E.; Lisjak, K.; Castellarin, S.D. Impact of leaf removal after berry set on fruit composition and bunch rot 'Sauvignon blanc'. VITIS—J. Grapevine Res. 2016, 55, 57-64. [CrossRef]

18. Wang, Y.; He, L.; Pan, Q.; Duan, C.; Wang, J. Effects of Basal Defoliation on Wine Aromas: A Meta-Analysis. Molecules 2018, 23, 779. [CrossRef]

19. Diago, M.P.; Ayestaran, B.; Guadalupe, Z.; Poni, S.; Tardaguila, J. Impact of prebloom and fruit set basal leaf removal on the flavonol and anthocyanin composition of Tempranillo grapes. Am. J. Enol. Vitic. 2012, 63, 367-376. [CrossRef]

20. Sternad Lemut, M.; Sivilotti, P.; Franceschi, P.; Wehrens, R.; Vrhovsek, U. Use of metabolic profiling to study grape skin polyphenol behavior as a result of canopy microclimate manipulation in a 'Pinot noir' vineyard. J. Agric. Food Chem. 2013, 61, 8976-8986. [CrossRef]

21. Frioni, T.; Zhuang, S.; Palliotti, A.; Sivilotti, P.; Falchi, R.; Sabbatini, P. Leaf removal and cluster thinning efficiencies are highly modulated by environmental conditions in cool climate viticulture. Am. J. Enol. Vitic. 2017, 68, 325-335. [CrossRef]

22. Šuklje, K.; Antalick, G.; Coetzee, Z.; Schmidtke, L.M.; Baša Cesnik, H.; Brandt, J.; du Toit, W.J.; Lisjak, K.; Deloire, A. Effect of leaf removal and ultraviolet radiation on the composition and sensory perception of Vitis vinifera L. cv. Sauvignon Blanc wine. Aust. J. Grape Wine Res. 2014, 20, 223-233. [CrossRef]

23. Suriano, S.; Savino, M.; Basile, T.; Tarricone, L.; Di Gennaro, D. Management of malolactic fermentation and influence on chemical composition of Aglianico red wines. Ital. J. Food Sci. 2015, 3, 310-319.

24. Iannini, C.; Mattii, G.B.; Rivelli, A.R.; Rotundo, A. Leaf removal and cluster thinning trials in Aglianico grapevine. Acta Hortic. 2007, 754, 241-248. [CrossRef]

25. Caccavello, G.; Giaccone, M.; Scognamiglio, P.; Forlani, M.; Basile, B. Influence of intensity of post-veraison defoliation or shoot trimming on vine physiology, yield components, berry and wine composition in Aglianico grapevines. Aust. J. Grape Wine Res. 2016, 22, 1-14. [CrossRef]

26. EEC 2676. Commission Regulation No 000/90 of 17 September 1990 Determining Community Methods for the Analysis of Wines. Off. J. Eur. Communities 1990, 81-83. Available online: https://eur-lex.europa.eu/legalcontent/EN/TXT/?uri=CELEX\%3A01990R2676-20050813 (accessed on 22 October 2020). 
27. Di Stefano, R.; Cravero, M.C. Methods for grape phenolic compound study. Riv. Vitic. Enol. 2001, 2, 37-45.

28. Trani, A.; Verrastro, V.; Punzi, R.; Faccia, M.; Gambacorta, G. Phenols, volatiles and sensory properties of Primitivo wines from the "Gioia Del Colle" PDO area. S. Afr. J. Enol. Vitic. 2016, 37, 139-148. [CrossRef]

29. Baiano, A.; Terracone, C.; Gambacorta, G.; La Notte, E. Phenolic content and antioxidant activity of Primitivo wine: Comparison among winemaking technologies. J. Food Sci. 2009, 74, C258-C267. [CrossRef]

30. Rice-Evans, C.; Miller, N. Measurement of the antioxidant status of dietary constituents, low density lipoprotein and plasma. Prostaglandins Leukot. Essent. Fat. Acids 1997, 57, 499-505. [CrossRef]

31. Labanca, F.; Faraone, I.; Nolè, M.R.; Hornedo-Ortega, R.; Russo, D.; García-Parrilla, M.C.; Chiummiento, L.; Bonomo, M.G.; Milella, L. New Insights into the Exploitation of Vitis vinifera L. cv. Aglianico Leaf Extracts for Nutraceutical Purposes. Antioxidants 2020, 9, 708. [CrossRef]

32. Revilla, E.; Ryan, L.M. Analysis of several phenolic compounds with potential antioxidant properties in grapes extracts and wines by high-performance liquid chromatography-photodiode array detection without sample preparation. J. Chrom. A 2000, 881, 461-469. [CrossRef]

33. Frioni, T.; Acimovic, D.; Tombesi, S.; Sivilotti, P.; Palliotti, A.; Poni, S.; Sabbatini, P. Changes in within-shoot carbon partitioning in Pinot noir grapevines subjected to early basal leaf removal. Front. Plant Sci. 2018, 9, 1-11. [CrossRef]

34. Poni, S.; Casalini, L.; Bernizzoni, F.; Civardi, S.; Intrieri, C. Effects of early defoliation on shoot photosynthesis, yield components, and grape composition. Am. J. Enol. Vitic. 2006, 57, 397-407.

35. Ivanišević, D.; Kalajdžić, M.; Drenjančević, M.; Puškaš, V.; Korać, N. The impact of cluster thinning and leaf removal timing on the grape quality and concentration of monomeric anthocyanins in Cabernet-Sauvignon and Probus (Vitis vinifera L.) wines. OENO One 2020, 1, 63-74. [CrossRef]

36. Casassa, L.F.; Harbertson, J.F. Extraction, evolution, and sensory impact of phenolic compounds during red wine maceration. Annu. Rev. Food Sci. Technol. 2014, 5, 83-109. [CrossRef] [PubMed]

37. VanderWeide, J.; Tombesi, S.; Castellarin, S.D.; Sabbatini, P. Canopy architecture and fruit microclimate, not ripening-related phytohormones, control phenylpropanoid accumulation in response to early leaf removal in 'Merlot' (Vitis vinifera L.) grapevines. Plant Physiol. Biochem. 2020, 157, 291302. [CrossRef] [PubMed]

38. Hunter, J.J.; Tarricone, L.; Volschenk, C.G.; Giacalone, C.; Melo, M.S.; Zorer, R. Grapevine physiological response to row orientation-induced spatial radiation and microclimate changes. OENO One 2020, 54, 411-433. [CrossRef]

39. Chorti, E.; Theocharis, S.; Boulokostas, K.; Kallithraka, S.; Kotseridis, Y.; Koundouras, S. Row orientation and defoliation effects on grape composition of Vitis vinifera L. Agiorgitiko in Nemea (Greece). E3S Web Conf. 2018, 50, 01039. [CrossRef]

Publisher's Note: MDPI stays neutral with regard to jurisdictional claims in published maps and institutional affiliations.

(C) 2020 by the authors. Licensee MDPI, Basel, Switzerland. This article is an open access article distributed under the terms and conditions of the Creative Commons Attribution (CC BY) license (http://creativecommons.org/licenses/by/4.0/). 